\title{
Effect of Cooling Rate and Retention Time of Masscuites in Sugar Losses in Beet Molasses \\ Mohamed, El-S. G. I. ${ }^{\text {; }}$ Mennat-Allah M. A. El-Geddawy ${ }^{2}$;M. B. Omar ${ }^{2}$ and S. I. El-Syiad ${ }^{2}$ \\ ${ }^{1}$ Production manager in (D.S.C) (Delta Sugar Company), Kafr El-Sheikh Governorate, Egypt. \\ ${ }^{2}$ Food Science \& Technology Department, Faculty of Agriculture, Assuit University, A. R. Egypt

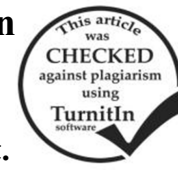

\section{ABSTRACT}

This research was carried out at (D.S.C) in beet campaign of (2017) to study the effect of cooling rate and retention time of masscuites in sugar losses in beet molasses. Beet roots and final molasses under studied were taken from the Factory. All samples of molasses were analyzed for the following:(total soluble solids TSS), sucrose, purity, non-sucrose, raffinose, reducing sugar and dextran. Also measured the specific gravity, color \% brix and $\mathrm{pH}$. The obtained results illustrated the following conclusions:The quality of sugar beet root was good value $82.23 \%$,(total soluble solids TSS), in molasses ranged from $79.70 \%$ to $79.8 \%$, sucrose 48.32 to $48.77 \%$, raffinose $1.41 \%$ to $1.71 \%$, reducing sugar $0.35 \%$ to $0.73 \%$, dextran $0.25 \%$ to $0.46 \%$, normal specific gravity with average of $1.415 \%$, color \% brix ranged from 30231.30 to 35765.70 and $\mathrm{pH} 8.8$ to $\mathrm{pH} 9.3$ in both production lines (1) and (2) respectively; Very low values of non-sugar to water ratio ( NS/W) with average of $1.57 \%$ and $1.51 \%$ in the two production lines (1) and (2) respectively. Decrease the sugar losses in final molasses to good values by increasing the quantity of cooling water and retention time inside the vertical cooling crystallizer for C- masscuites in both production line (1) and (2) in Delta Sugar Company.

Keywords: Sugar beet, molasses, sucrose, beet juice, Quality, Cooling crystallization and masscuites.

\section{INTRODUCTION}

In sugar beet operation, the amount of sugar lost to molasses is the largest loss (about $80 \%$ of unrecoverable of sugar ends up in molasses ). So that, to profitability of any beet sugar factory. The easiest way to control molasses exhaustibility is to determine the purity of final beet molasses . (the lower the purity of molasses, the lower the amount of sugar lost to molasses and so, the higher is the sugar production. Production of final molasses with low purity is the best gained that a beet factory can get. So that, exhaustibility of molasses is considered, the most important subject in operation of beet factory. Try to achieve the right massecuite concentration 93,5 to $95 \%$ Brix for high - raw and 94,5 to $96 \%$ Brix for low - raw massecuite at all stages ( the higher the massecuite concentration, the lower is the purity of the mother liquor and consequently, the lower is the molasses purity. Molasses could be defined as a solution containing sugar and non- sugar at the final stage of crystallization. Produced by about $4-5 \% \mathrm{OB}$ (of beet), and contain less than $48 \%$ sugar (sucrose and invert sugar) and 79,5-82\%Brix. Such a molasses contain purity of about $60 \%$ or less Asadi (2007). Consequently, the main objective of this investigation is to study the effect of cooling rate and retention time of masscuites in sugar losses in final beet molasses.

\section{MATERIALS AND METHODS}

\section{Materials:}

Beet roots and final molasses were obtained from (D.S.C) in beet campaign of (2017).

Methods:

Physical analysis:

Total soluble solids (T.S.S.):

Total soluble solids(brix) of fresh samples were determined by using fully automatic digital refractometer, model ATR-S (04320), 0 - 95\%Brix, by the method of Delta sugar Company procedure.

Specific gravity:

Specific gravity was determined according to A.O.A.C (1995) at $20^{\circ} \mathrm{C}$.
pH- value:

All molasses Samples should be diluted to 60

brix and cooled to room temperature before $\mathrm{pH}$

measurement by Olbrich (1963).

Chemical analysis:

Moisture content:

The Moisture content was measured according to the method recommended in A.O.A.C (1995).

Moisture content $\%=100$ - total soluble solids (brix) $\%$ Sucrose content:

Sucrose content was determined using digital saccharimeter by Le Docte (1977).

Reducing sugar:

Reducing sugar content of beet roots samples were determined using Ofner's volumetric methods as described in A.O.A.C. (1990)

\section{Dextran content:}

Dextran in sugar beet molasses samples were determined according to procedure of Roberts (1983).

Minerals content of molasses:

Alpha amine nitrogen, sodium and potassium (m.eqv / $100 \mathrm{gm}$ beet) were determined according to Brown and Lillan (1964), the results calculated as milli equivalents / $100 \mathrm{~g}$ sugar beet roots.

$$
\text { Purity } \%=\frac{\text { sucrose } \%}{\text { T.S.S } \%} \times 100
$$

Quality of beet $=(\mathrm{SR} .100) / \mathrm{pol} . \mathrm{SR}=(\mathrm{pol}-0.29)-0.343(\mathrm{k}+\mathrm{Na})-$ $\alpha \mathrm{N}(\mathbf{0 . 0 9 3 9 )}$

Sugar losses in molasses (SL) percentage were determined using the following equation:

$$
\mathbf{S L}=\mathbf{0 . 3 4 3}(\mathbf{K}+\mathbf{N a})+\alpha \cdot \mathbf{N}(\mathbf{0 . 0 9 4})+\mathbf{0 . 2 9}
$$

Where: Pol $=$ Sucrose $\%, K=$ Potassium, $N a=$ Sodium,$\alpha-\mathrm{N}=$ Alpha-amino nitrogen, $\mathbf{S R}=$ Sugar recovery and T.S.S $=$ total soluble solids by Silin and Silina (1977).

\section{RESULTS AND DISCUSSION}

Chemical analysis of beet roots in (D.S.C) in beet campaign of (2017).

It is important to evaluate the chemical quality of sugar beet roots in order to evaluate their quality for sugar production and molasses, because it well be known that the quality of molasses depends mainly on the nature of its sugar beet. Root yield and technical 
quality of sugar beet are strongly influenced by weather conditions. The data in Table (1) demonstrate that, as the Potassium, Sodium and Alpha-amino nitrogen contents are relatively suitable values 6.29, 2.06 and 2.831 (m.eqv / $100 \mathrm{gm}$ beet) respectively, in sugar beet, so the quality of sugar beet roots is in good value $82.23 \%$. The dry substance $20.90 \%$ and sugar $19.35 \%$. The obtained data are in similar with Asadi (2007) who found that, sugar beet juice is mainly made up of $25 \%$ dry substance, 15 to $20 \%$ sucrose and $2.5 \%$ nonsucrose.

Table 1. Chemical analysis of sugar beet roots in Delta Sugar Company during working season (2017).

\begin{tabular}{lc}
\hline Parameters & Values \\
\hline Dry solids \% & 20.90 \\
Sugar \% & 19.35 \\
Non-sugar \% & 1.55 \\
Potassium & 6.29 \\
Sodium & 2.06 \\
Alpha-amino nitrogen & 2.83 \\
Quality \% & 82.23 \\
\hline * Each value was an average of three determinations
\end{tabular}

Chemical and physical analysis of Delta beet molasses during working season (2017) in both production line (1) and (2).

Beet molasses is the run off syrup from the final stage of crystallization, usually contains about $48 \%$ sugar and $80 \%$ dry substances (Brix) Asadi (2007). The chemical and physical characteristics of beet molasses during processing of (2017) beet campaign in both production line (1) and (2) are given in Table (2). The results reflects the following indications; The brix of beet molasses samples were ranged from $79.70 \%$ to 79.80 and it contain sucrose with average of $48.55 \%$ and high values of raffinose, reducing sugar, dextran and color $\%$ brix in production line (2) $1.71 \%, 0.73 \%$ $046 \%$ and $35765.70 \%$ brix more than production line (1) $1.41 \%, 0.35 \%, 0.25 \%$ and $30231.30 \%$ brix respectively. These results are confirmed by Asadi (2007) who concluded that, the color of molasses ranged from 40000 to 70000 . The purity is ranged from 60.55 to $61.19 \%$. The specific gravity of molasses in normal value is about $1.41 \%$. Also, $\mathrm{pH}$ of beet molasses with average of 9.1.These results are agreement with that reported by AL-tantawy (2012) who demonstrates the following results for analysis of beet molasses in Delta Sugar Company. The purity is ranged from 59.52 to $61.92 \%$, the color \%brix is 28267 to 51630 , and the specific gravity is $1.41 \%$ and the $\mathrm{pH} 8$ to 9.5 during different periods of campaign.
Table 2. Chemical and physical analysis of Delta beet molasses during working season (2017) in both production line (1) and (2).

\begin{tabular}{lcc}
\hline Parameters & $\begin{array}{c}\text { production } \\
\text { line(1) }\end{array}$ & $\begin{array}{c}\text { production } \\
\text { line(2) }\end{array}$ \\
\hline Total solids(Brix)\% & 79.80 & 79.70 \\
Sucrose \% & 48.32 & 48.77 \\
Raffinose \% & 1.41 & 1.71 \\
Rducing sugar \% & 0.35 & 0.73 \\
Dextran \% & 0.25 & 0.46 \\
Color \% Brix & 30232.30 & 35765.70 \\
Specific gravity \% & 1.416 & 1.414 \\
Purity\% & 60.55 & 61.19 \\
pH & 9.3 & 8.8 \\
\hline
\end{tabular}

* Each value was an average of three determinations

Calculation of non-sugar to water (NS / W) ratio for beet molasses in Delta Sugar Company in both production line (1) and (2) during working season (2017). Although sucrose solubility in water is dependent only on the temperature, its solubility in impure solution depends on three factors, temperature, non-sucrose and non-sucrose characteristics Asadi (2007). From the results in Table (3) and Table (4) the non-sugar to water (NS / W) ratio for beet molasses was calculated by the method of Delta Sugar Factories using the following equations:

Water $(W)=100-$ dry solids (Brix), Non-sucrose (NS) = dry solids (Brix) - sucrose

It could be noticed that, an important ratio that relates to sucrose solubility (and to molasses formation) is the non-sugar to water (NS / W) ratio in the massecuite, as the NS/W ratio changes, so changes the sucrose solubility in the syrup. This ratio can indicate whether crystallization has reached the final stage. The results in both production line (1) and (2) shows very low values of the non-sugar to water (NS / W) ratio in the massecuite, with average $1.54 \%$ ), and this is very low value in beet sugar industry comparable to Van der poel et al. (1998) who showed that, in beet sugar manufacture is usually reached at non-sugar/ water ratio between 3,5 to 5 and in cane sugar manufacture between 3.5 to 8. Also Asadi (2007) who reported that, the functional maximum NS / W ratio is about 4.8 to 5 $\%$.When this value is reached, molasses exhaustibility has reached its maximum limit, high (NS / W) ratio decrease sucrose lost in final molasses (decrease the purity of molasses) due to decreasing the amount of water in molasses.

Table 3. Determination of non-sugar to water (NS / W) ratio for C-masscuites in production line (1) in Delta Sugar Company during working season (2017).

\begin{tabular}{lcccccc}
\hline Replicate & Brix(DS) & Sugar & Purity & NS & Water & NS / W \\
\hline 1 & 79.62 & 48.46 & 60.86 & 31.16 & 20.38 & 1.53 \\
2 & 79.90 & 47.86 & 59.90 & 32.04 & 20.10 & 1.59 \\
3 & 80.12 & 48.71 & 60.80 & 31.41 & 19.88 & 1.58 \\
4 & 80.11 & 48.33 & 60.33 & 31.78 & 19.89 & 1.60 \\
5 & 79.77 & 48.31 & 60.56 & 31.46 & 20.23 & 1.56 \\
\hline Average & 79.90 & 48.33 & 60.49 & 31.51 & 20.10 & 1.57 \\
\hline
\end{tabular}

* Each value was an average of three determination 
Table 4. Determination of non-sugar to water (NS / W) ratio for C-masscuites in production line (2) in Delta Sugar Company during working season (2017).

\begin{tabular}{lcccccc}
\hline Replicate & Brix(DS) & Sugar & Purity & NS & Water & NS / W \\
\hline 1 & 79.59 & 50.06 & 62.90 & 29.53 & 20.41 & 1.45 \\
2 & 80.31 & 48.92 & 60.92 & 31.39 & 19.69 & 1.59 \\
3 & 79.63 & 49.04 & 61.59 & 30.59 & 20.37 & 1.50 \\
4 & 79.67 & 48.53 & 60.91 & 31.14 & 20.33 & 1.53 \\
5 & 79.80 & 49.88 & 62.51 & 29.92 & 20.20 & 1.48 \\
\hline Average & 79.80 & 49.29 & 61.77 & 30.51 & 20.20 & 1.51 \\
\hline
\end{tabular}

* Each value was an average of three determinations

Determination of sugar losses in molasses $\%$ of beet in relation to quantity of cooling water in both production line (1) and (2) during working season (2017). Crystallization is one of the most effective separation techniques, providing an impurityelimination effect of up to $99.9 \%$. In sugar beet factories usually use a three-stage Crystallization process A, B and $\mathrm{C}-$ Crystallization. The mother liquor of the third stage is called molasses. Cooling crystallization is used to finalize molasses exhaustibility by removing all sugar possible from the last mother liquor (molasses) . the decrease in temperature of massecuite cause the in the mother liquor to hold less sugar (solubility decrease with decreasing temperature. When massecuite is cooled in cooling crystallizer excess sugar crystalize as temperature drops. As we cool the massecuite in the cooling crystallizer to about $45{ }^{\circ} \mathrm{C}$ (the usual temperature of the cooling crystallizer )its solubility decrease, and consequently molasses with lower purity produced after the massecuite centrifuged . But cooling the massecuite below $45{ }^{\circ} \mathrm{C}$ rarely results in lower molasses purity, this is due to the low crystallization rates because of high viscosity al lower temperature. Asadi (2007) . The proportional relationship of sucrose losses in molasses was calculated according the procedure of Delta Sugar Company using the following equation:

Sucrose losses in molasses\% $\%$ Brix\% $\%$ Purity\% * Yield of molasses\% / 10000

From table(5) it could be noticed that, by increasing the quantity of cooling water inside the cooling crystallizer for $\mathrm{C}$ - masscuites in both production line (1) and (2) the sugar losses in final molasses decrease to 2,23 and $2,06 \%$ of beet respectively at the same quantity of cooling water $30 \mathrm{~m}^{3} / \mathrm{h}$. The results are confirmed by Van der poelet al. (1998) who reported that, for the good performance of cooling crystallizer for $\mathrm{C}$-sugar, adequate heat transfer surface area to operate at a digressive cooling rate with acceptable temperature differences between the magma and cooling water (10$15 \mathrm{k}$ ) and the flow pattern between the magma and the cooling water should be as close as possible to an ideal countercurrent. Also the obtained data are comprable with Asadi (2007) who mentioned that, the low-raw massescuite can be in optimum results when it treated in the cooling crystallizer at 45 to $55^{\circ} \mathrm{C}$. At a constant end temperature in cooling crystallization, an increase in the non- sugar/ water ratio in the saturated state should result in a lower mother liquor theoretically.
Table 5. Determination of sugar losses in molasses\% of beet in relation to quantity of cooling water in both production line (1) and (2) during working season (2017).

\begin{tabular}{lccc}
\hline $\begin{array}{l}\text { Quantity of } \\
\text { cooling water }\end{array}$ & \multicolumn{3}{l}{ Sugar losses in final beet molasses \% of beet } \\
\cline { 2 - 4 } & $\begin{array}{c}\text { Production } \\
\text { line(1) }\end{array}$ & $\begin{array}{c}\text { Production } \\
\text { line(1) }\end{array}$ & Average \\
\hline $15 \mathrm{~m}^{3} / \mathrm{h}$ & 3.29 & 2.95 & 3.12 \\
$20 \mathrm{~m}^{3} / \mathrm{h}$ & 2.64 & 2.54 & 2.59 \\
$25 \mathrm{~m}^{3} / \mathrm{h}$ & 2.49 & 2.29 & 2.39 \\
$30 \mathrm{~m}^{3} / \mathrm{h}$ & 2.23 & 2.06 & 2.15 \\
\hline
\end{tabular}

* Each value was an average of three determinations

Determination of sugar losses in molasses $\%$ of beet in relation to retention time of masscuites inside the cooling crystallizer in both production line (1) and (2) during working season (2017).

From results obtained in table(6) it could be showed that, an inversely proportional relationship between sucrose losses in final molasses \% of beet and retention time of masscuites inside the cooling crystallizer in both production line (1) and(2) reached to $1,99 \%$ and $1,84 \%$ respectively by increasing retention time to 45 hour. The results are confirmed by Van der poelet al. (1998) who reported that, for the good performance of cooling crystallizer the retention time more than 40 hour are essential for C-sugar. The obtained results are confirmed also by Asadi (2007) who found that, the low-raw massescuite gives an optimum results when treated in the cooling crystallizer with sufficient retention time more than 24 hours.

Table 6. Determination of sugar losses in molasses\% of beet in relation to retention time of masscuites inside the cooling crystallizer in both production line (1) and (2) during working season (2017).

\begin{tabular}{lcc}
\hline \multirow{2}{*}{ Retention time(h) } & \multicolumn{2}{c}{ Sugar losses in final beet molasses \% of beet } \\
\cline { 2 - 3 } & Production line(1) & Production line(1) \\
\hline 30 hour & 2.87 & 2.54 \\
35 hour & 2.52 & 2.30 \\
40 hour & 2.31 & 1.90 \\
45 hour & 1.99 & 1.84 \\
\hline
\end{tabular}

* Each value was an average of three determinations

\section{REFERENCES}

A.O. A. C (1995).Association Official Analytical Chemists. Official Methods of Analysis of the 16 ED.A .O. A. C International, Washington, D. C, U.S.A.

A.O.A.C. (1990).“Official Methods of Analysis. Association of Official Analytical Chemists. Washington 25 D.C., USA. 
Al-tantawy, K.S.A. (2012). Studies on alcoholic fermentation for beet molasses.M.Sc.thesis, Sugar Techn. Research Inst., AssiutUnive.

Asadi M. (2007).Beet-Sugar Handbook.John Wiley and Sons, Inc., Hoboken, New Jersey, pp.99-289.

Brown, J.D and O. Lilland (1964).Rapid determination of potassium and sodium by flam photometry.Proc. Amer. Soc. Hort. Sci., 48, 341-316.

Le Docte, A. (1977). Commercial determination of sugar in sugar beet using the socks sugar J., 29, 488-492.

Olbrich H., (1963). Principles sugar technology (second edition, Ed . by Honig, P.Vol.III, Chap.13,Pp.501534) Elsevier Publishing Co., New York .
Roberts, E.J. (1983).A quantitative methods for dextran analysis. International sugar Journal, 85 (1025), 1013.

Silin P.M., and Silina N.P.,(1977) . Chemical control in sugar technology .Food Technol., Pub. USSR, Pp. 120-126.

Van der Poel, P.W., Schiweck, H., Schwartz, T., (1998). Sugar Technology.Beet and Cane Sugar Manufacture.Verlag Dr. Albert Bartens KG- Berlin.

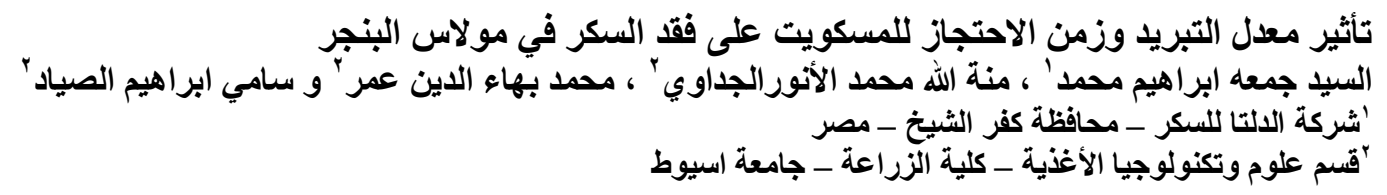

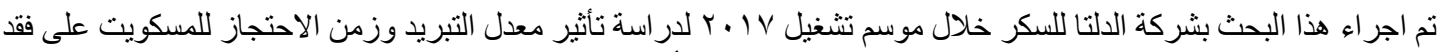

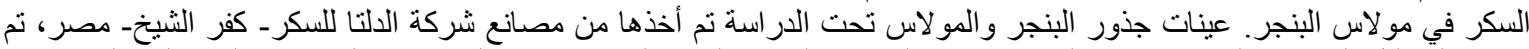

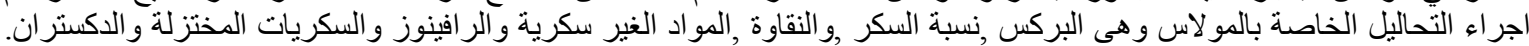

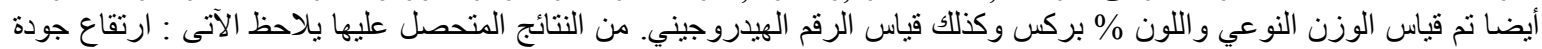

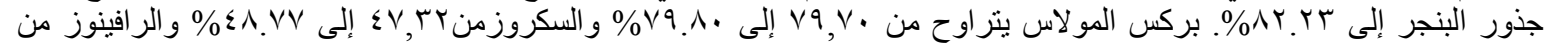

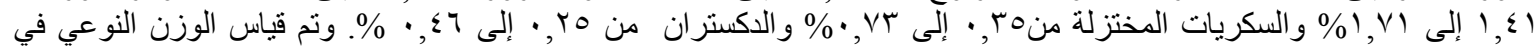

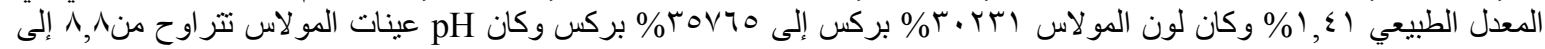

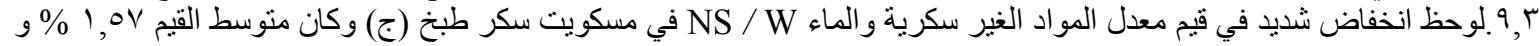

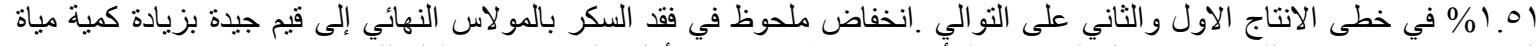

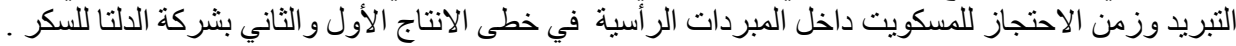

